\title{
Infrared thermography for the use in facial surgery
}

\author{
Walter Wild*, Jörg Ritzke**, Burkhard Kramp**, Jan-Hendrik Lenz ${ }^{* *}$, Karsten \\ K.H. Gundlach**
}

\author{
Rostock University \\ * Institute for Measurement and Control Techniques \\ ** Faculty of Medicine \\ Albert-Einstein-Str. 2, D-18051 Rostock, \\ phone ++49 / 381 / 498 3100, fax ++49 / 381 / 4983098 \\ e-mail: walter.wild@mbst.uni-rostock.de
}

\begin{abstract}
Today infrared thermography seems to be a useful and non-invasive tool in medical research as well as in clinical practice [1]. The technique enables precisional control of heat produced by drilling and screwing in surgical management of maxillofacial fractures.

Therapy of midfacial fractures requires accurate reduction and fixation of bones to prevent mobility of fragments during fracture healing. This can be achieved by using titanium miniplates and screws. But drilling and screwing in bones shall be performed with an integrated cooling device for tissues and materials to avoid necrosis of hard and soft tissues. Even damage of nerval tissue and loss of the implants are possible. However, this can be prevented by the use of infrared thermography to measure temperatures on surfaces intraoperatively. In this study first observations were made during 36 experimental drillings on macerated human skulls. Then intraoperative measurements were done during treatment of 13 midfacial fractures.
\end{abstract}

\section{Introduction}

Maxillofacial fractures are due to assaults, falls, road traffic accidents, sports injuries, industrial and war injuries. All of them are considered to be severe injuries with dislocation of either one major bony fragment (due to blunt forces) or multiple minor fragments in so-called comminuted fractures.

The midface is a complex three-dimensional structure. The load-bearing areas are comparable with a bilateral framework containing transeptions and cavities. When strong forces act upon the mid-face typical fracture lines occur in three main levels (figure 1). Therefore positioning of plates has to be performed in typical locations (figure 2). Emergencies should be operated on immediately, in other cases a treatment within 24 hours is aimed at. Midfacial fracture treatment should begin by stepwise reconstruction of load-bearing structures of the facial skeleton: Reduction, retention and fixation of the fractured bones. Stabilization of the reduced fragments is achieved by using plates and screws [2].

Modern osteosynthesis of bones in midfacial fractures is carried out by using miniplates and screws made of titanium. Various plating systems are applied by maxillofacial surgeons today. The rigidity of osteosynthesis depends on the dimensions of plates and screws. The individual type of plating system is described by the diameter of screws. 
Titanium microplate systems ( 0.8 up to 1.0 millimeters) and miniplate systems ( 1.5 to 2.0 millimeters) are most frequently used. Removal of plates and screws is taken care of by a second operation later on. In the last decade plating systems of bioresorbable materials (polylactic acid - PLLA, polyglycolic acid - PGA, polydioxanone - PDS ) were developed for midfacial fracture management, especially in children. Secondary surgery becomes superfluous then [3].

Drilling and screwing can cause high temperatures, leading to damage of bone and soft tissue cells. This may result in prolonged wound healing, non-union of bone and loss of osteosynthesis materials. Major temperatures can even cause osteonecrosis and damage of peripheral nerves. Therefore sufficient cooling of materials and tissues is mandatory. The non-invasive thermography allows a differentiated estimation of local heat spots at hard and soft tissues [1,4]. This in turn enables control of treatment intraoperatively and high temperatures can be avoided.

\section{Material and Methods}

First, the optimal distance for the thermovision camera (AGEMA 470, range from 2 to $5 \mu \mathrm{m}$ ) to collect data from macerated human skulls was studied experimentally.

Then measurements were taken with and without the use of continuous saline cooling when performing drilling and screwing using miniplates and screws (System Leibinger 2.0) at typical load-bearing structures of the facial skeleton.

Finally intraoperative observations were made during the management of 13 midfacial fractures in patients. Attention was taken to continuous and effective saline cooling during drilling and screwing. All thermovisional measurements were documented and completed by additional digital photographies.

Any data achieved from thermographic measurements were stored digitally. Major differences in temperatures were listed.

\section{Results}

\subsection{Experimental observations on macerated skulls}

36 drillings were made using saline cooling in the midface of moistened and warmed $\left(37^{\circ} \mathrm{C}\right)$ macerated skulls. In two cases major temperatures $\left(>40{ }^{\circ} \mathrm{C}\right)$ were measured. 34 more drillings were made in dry $\left(22^{\circ} \mathrm{C}\right)$ macerated skulls without cooling. High temperatures of $60^{\circ} \mathrm{C}$ (arithmetic mean) were noted (table 1). Measurements were carried out again when using self-cutting screws. The resulting temperatures differed even when comparing data from the outer with those from the inner surfaces of these skulls. In any case temperatures on the resulting holes were always dangerous $\left(41,7^{\circ} \mathrm{C}\right.$ up to $82,4^{\circ} \mathrm{C}$; figure 3 ) even when using saline cooling. Without cooling temperature rises varied between $90^{\circ} \mathrm{C}$ and $140^{\circ} \mathrm{C}$. 
Table 1. Temperature peaks in ${ }^{\circ} \mathrm{C}$ as measured at drilling on macerated skulls

\begin{tabular}{|l|c|c|}
\hline Location of miniplates & $\begin{array}{c}\text { saline cooling } \\
\text { Maximum of } \\
\text { temperatures found }\end{array}$ & $\begin{array}{c}\text { without cooling } \\
\text { Maximum of temperatures } \\
\text { found }\end{array}$ \\
\hline frontal bone & 33.6 & 137.5 \\
\hline nasal bone & 40.1 & 199.5 \\
\hline lateral orbit & 43.6 & 128.5 \\
\hline infraorbital margin & 26.8 & 117.8 \\
\hline zygomatic arch & 25.7 & 164.4 \\
\hline crista zygomaticoalveolaris & 26.2 & 75.0 \\
\hline apertura piriformis & 25.7 & 121.8 \\
\hline
\end{tabular}

\subsection{Intraoperative observations}

Measurements were carried out in operating theatres when performing surgical management of midfacial fractures during clinical surgery routine. In "life" osteosythesis the resulting heat of procedures was reduced not only by continuous saline cooling but also by the circulating blood. Evaluation of 114 drillings revealed that the temperature rose up to $62.8{ }^{\circ} \mathrm{C}$ (maximum) when using a syringe for cooling (figure 4). In contrats thereto, using a handpiece with integrated spray for cooling resulted in temperature rises of only $26{ }^{\circ} \mathrm{C}$ (arithmetic mean). Screwing did not cause remarkable rises of temperatures.

\section{Discussion and Conclusion}

Measuring of temperature (e.g. for fever) is well known in ancient and modern medicine. Thermovision by means of infrared light is a touchless technique and seems to be valuable for research as well as in day to day medicine [1, 4].

The experimental and clinical observations made in this study have shown the importance of continuous cooling when performing osteosynthesis in the midface. Drilling without cooling resulted in temperature rises of about $100{ }^{\circ} \mathrm{C}$. Saline cooling integrated in the handpiece seems to be most effective. The use of a syringe for cooling is not recommended because temperature rises of more than $50{ }^{\circ} \mathrm{C}$ were measured and can cause tissue necrosis and even loss of implants. Deep bone drilling should be performed carefully; therefore the speed of the drills should be reduced. However, no important rise of temperatures were measured intraoperatively during screwing.

The advantages of thermovision by means of infrared light for the observation of midfacial osteosynthesis are obvious:

- No delay between generation and perception of local heat

- Temperature measurement on a surface area is possible

- Dynamical temperature changes can be noted in process.

Digital photography seems to be a valuable supplement as the camera enables an intraoperative close-up view.

\section{REFERENCES}

[1] Balageas D., Busse G., Carlomagno C. M., Svaic S.: Proceedings 6. QIRT 2002, Biomedical Application, p. 253-283, Dubrovnik 2002 
[2] Austermann K. H.: Frakturen des Gesichtsschädels. In: Schwenzer, N., M. Ehrenfeld (Hrsg.): Zahn-Mund-Kiefer-Heilkunde. Band 2: Spezielle Chirurgie. Thieme, Stuttgart 2002 ,

[3] Härle F., Champy M., Terry B. C.: Atlas of Craniomaxillofacial Osteosynthesis. Miniplates, Microplates, and Screws. Thieme, Stuttgart 1999

[4] Wild W., Schütte S. R., Pau H. W., Kramp B., Just T.: Infrared thermography as a non invasive application for medical diagnosis, XVII. IMEKO World Congress, Proceedings, p. 1744-1748, Dubrovnik 2003

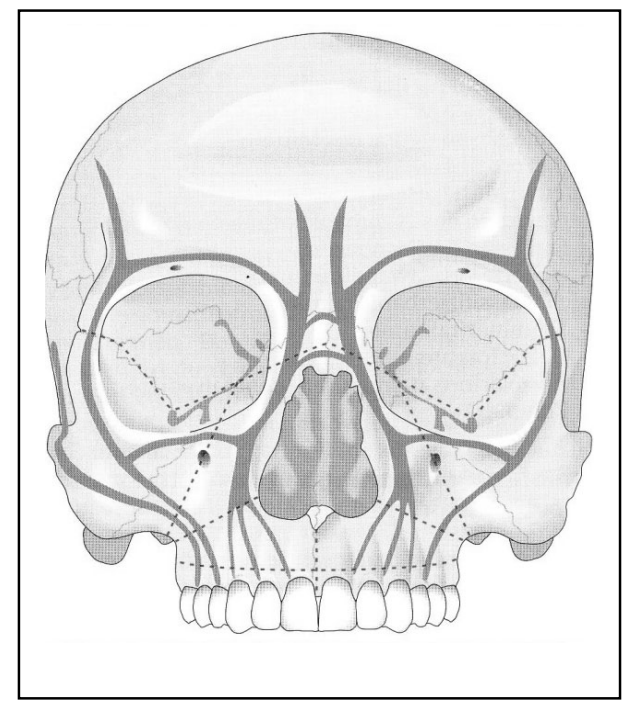

Fig. 1. Frame-like construction of the midface. Load-bearing structures grey, levels of fracturing - red [2].

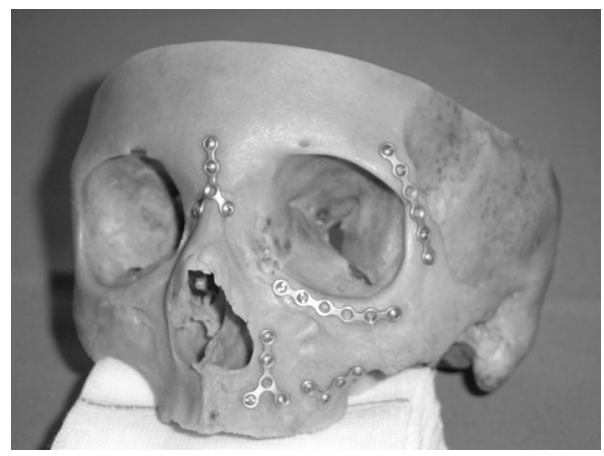

Fig. 2. Typical position of miniplates in the midface (on macerated skull) 

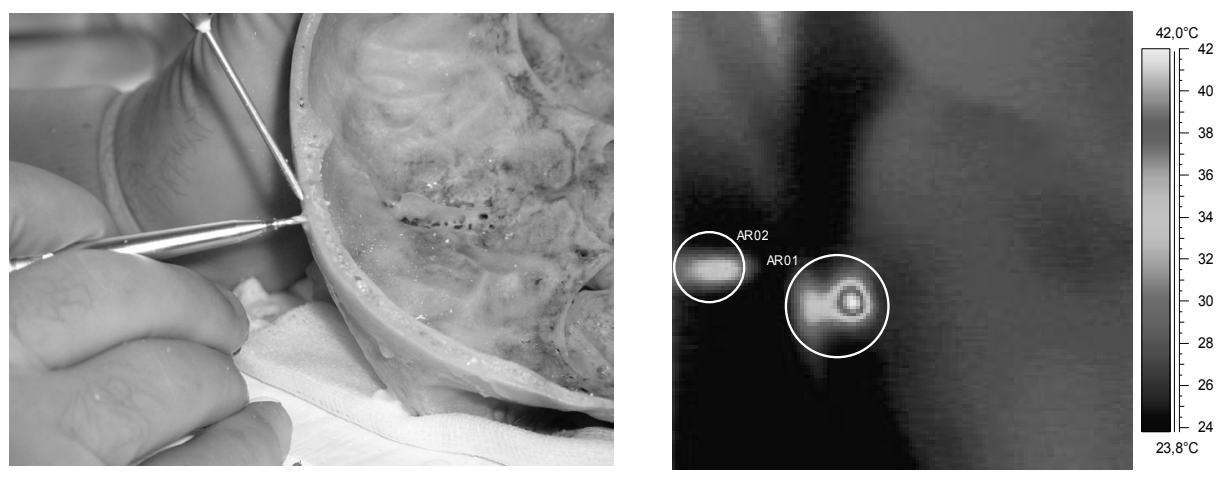

Fig. 3. Drilling at the frontal bone. Main direction of the camera to bone cut.
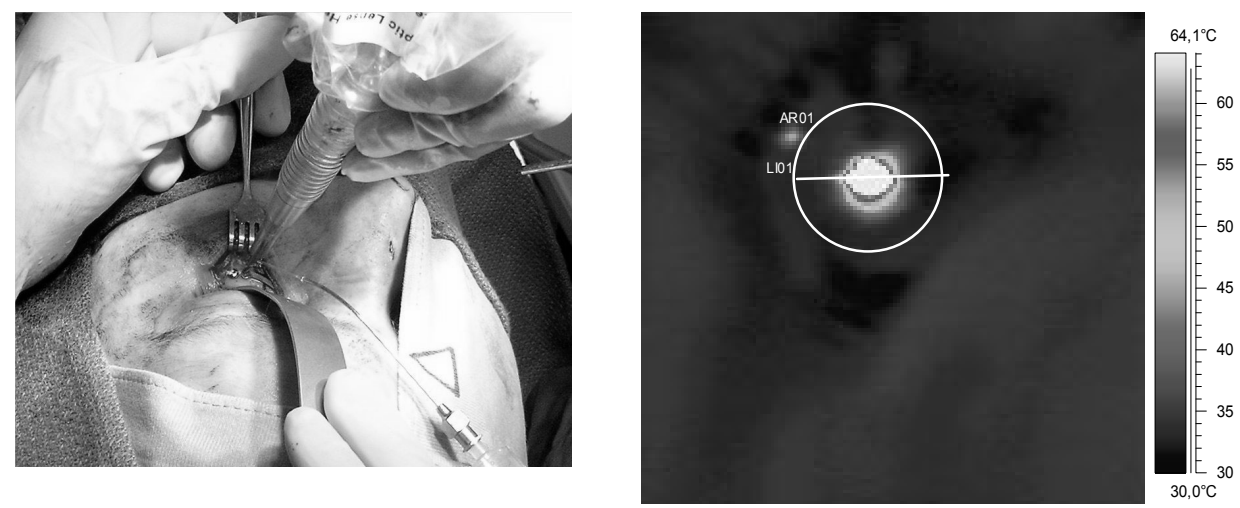

Fig. 4. Intraoperative view. Application of miniplate at the infraorbital margin. Note the syringe used for cooling. 
http://dx.doi.org/10.21611/qirt.2004.006 